\title{
Risk Factors for Hysterectomy Among Mexican-American Women in the U.S. Southwest
}

\author{
SUSAN I. HAUTANIEMI ${ }^{1}$ AND LYNNETTE LEIDY SIEVERT ${ }^{2 *}$ \\ ${ }^{1}$ Population Studies Center and ICPSR, University of Michigan, Ann Arbor, Michigan 48106 \\ ${ }^{2}$ Department of Anthropology, University of Massachusetts at Amherst, Massachusetts 01003
}

\begin{abstract}
The purpose of this study was to assess risk factors associated with a history of hysterectomy among Mexican-American women living in the United States Southwest. MexicanAmerican women ages 20-74 at time of interview were defined as a subpopulation among adults in the Hispanic Health and Nutrition Examination Survey (HHANES), 1982-1984. Language preference, reproductive history, level of education, poverty status, generation of immigration, marital status, and insurance coverage were examined in relation to risk of hysterectomy using weighted tabulation and logistic regression for data resulting from complex survey designs. Heretofore, language preference has not been a variable considered in relation to risk of hysterectomy. In the HHANES, over $60 \%$ of women who spoke English most often rather than Spanish reported a history of hysterectomy. Women who had previously been pregnant were almost four times as likely (odds ratio 3.972) to have had a hysterectomy compared to women who had never been pregnant. Women who expressed any preference for English were twice as likely (odds ratio $2.050)$ to have had a hysterectomy than were those who responded that they exclusively preferred Spanish. Age, higher levels of education, and higher economic status also increased the risk of hysterectomy. In contrast, reproductive history, marital status, prior tubal ligation, generation of immigration, and health insurance did not have substantial effects on the risk of hysterectomy. This study suggests that, in the future, the effect of language preference should not be overlooked when considering risk factors for hysterectomy. Am. J. Hum. Biol. 15:38-47, 2003.

(c) 2002 Wiley-Liss, Inc.
\end{abstract}

The present study was prompted by an analysis of age at menopause among Mexican-American women drawn from the Hispanic Health and Nutrition Examination Survey (HHANES), 1982-1984. In carrying out that analysis, it was observed that among postmenopausal Mexican-American women $37 \%$ of those who responded that they spoke Spanish most often reported hysterectomies, compared to $68 \%$ who used English most often (Leidy, 1998). This result was consistent with the assumption that Spanish-speaking Mexican-American women would have fewer hysterectomies because of language-related barriers to health care (Derose and Baker, 2000; Woloshin et al., 1995), fewer visits to a physician (LilliBlanton et al., 1993), and lack of health insurance (Estrada et al., 1990; Mays et al., 2000; Solis et al., 1990; Torre et al., 1996). However, the high rate of hysterectomies among postmenopausal English-speaking MexicanAmerican women $(68 \%)$ was a surprising result that suggested a cohort of women who were, perhaps, medically over-served.

This present study further investigates the relationship between language preference (a broader question than that of language used most often) and risk of hysterectomy in the Mexican-American portion of the HHANES, using appropriate weighting techniques to produce correct population estimates (Delgado et al., 1990). This study examines whether language preference remains an explanatory variable for risk of hysterectomy and whether risk of hysterectomy remains elevated among English-speakers after controlling for other reproductive and demographic risk factors.

The finding that language preference was, 20 years ago, related to risk of hysterectomy alerts practitioners to the possibility that language preference may now target a cohort of older women at increased risk of osteoporotic fractures, particularly if the hysterectomies were accompanied by oophorectomies. Cohort membership shapes health behavior, diet, economic history, educational opportunities, and particular health risks-including exposure to surgical pro-

*Correspondence to: Lynnette Leidy Sievert, Dept. of Anthropology, Machmer Hall, UMass at Amherst, Amherst, MA 01003-4805. E-mail: leidy@anthro.umass.edu

Received 28 January 2002; Revision received 24 June 2002; Accepted 5 July 2002

Published online in Wiley InterScience (www.interscience. wiley.com). DOI: 10.1002/ajhb.10110 
cedures (Elder, 1985; Garcia and Cutler, 1984; Riley, 1982; James et al., 1996). Therefore, past information about health care utilization may be quite useful for targeting the health risks of those who are now older. In other words, the HHANES data retain clinical significance, even 20 years later, because an early surgical menopause in 1982-1984 could signal a risk factor for osteoporosis in 2003.

Currently, hysterectomy is the second most common major surgery for women of reproductive age, following cesarean sections (Bernstein et al., 1997; Pokras and Hufnagel, 1988). Each year, approximately 600,000 hysterectomies are performed in the United States (Farquhar and Steiner, 2002; Lepine et al., 1997). By age $60,37 \%$ of all U.S. women have undergone this procedure (Pokras and Hufnagel, 1988). Leiomyoma (fibroids) is the most common indication for hysterectomy, along with abnormal uterine bleeding, endometriosis, uterine prolapse, and gynecological malignancies (Lepine etal., 1997). Within the U.S., hysterectomy rates vary across geographic regions (Bernstein et al., 1992; Haas et al., 1993; NYSDH, 1988). Factors related to a higher risk of hysterectomy include lower education, occupational status and income levels (Brett et al., 1997; Kjerulff et al., 1993a,b; Leidy, 1999; Marks and Shinberg, 1997; Meilahn et al., 1989) previous tubal ligation (Goldhaber et al., 1993; Hillis et al., 1998), having a male physician or a physician with less recent medical training (Bickell et al., 1994), insurance coverage (Geller et al., 1996), use of IUD, and history of miscarriage (Brett et al., 1997; Geller et al., 1996).

A 1985 Senate subcommittee report characterized knowledge about minority women's experience of hysterectomy as "sparse, largely historical and anecdotal" (Kjerulff et al., 1993a). In subsequent years, some studies have indicated a higher rate of hysterectomy among black or nonwhite women compared to white women (Meilahn, 1989; Mort et al., 1994; Carlisle et al., 1995; Chandra, 1998), while other investigators have demonstrated no racial or ethnic differences in hysterectomy rates (Lepine et al., 1997; Kjerulff et al., 1993b). Hysterectomy for fibroids is found to be more common in black women compared to white women (Brett et al., 1997; Kjerulff, 1993a).

There is conflicting evidence regarding the prevalence of hysterectomies among Latino women (Carlisle et al., 1995; Chandra, 1998). The National Survey of Family Growth data, 1973-1995, suggested lower rates of hyster- ectomy among Hispanic women compared to non-Hispanic white women (Chandra, 1998). In contrast, other studies have found a higher rate of hysterectomy among Latino women (Carlisle et al., 1995). An analysis of the HHANES, 1982-1984, demonstrated that Mexican-American women have higher rates of hysterectomy than do either Puerto Rican or Cuban-American women (StroupBenham and Trevino, 1991).

Although the risk of osteoporotic fracture is lower among Mexican-American (Bauer et al., 1986; Looker et al., 1995; Taaffe et al., 2000) and Mexican women compared to U.S. whites, the prevalence is not insubstantial. Mexican-American women drawn from NHANES III, 1988-1991, demonstrated osteoporosis as defined by WHO diagnostic criteria in $16 \%$ of femur neck, $19 \%$ of trochanter, and $16 \%$ of intertrochanter regions (Looker et al., 1995). These age-adjusted prevalence rates for osteoporosis among MexicanAmerican women were lower than among non-Hispanic white women, but higher than among non-Hispanic black women. Similarly, a multisite study in Mexico found the prevalence of osteoporosis of the lumbar spine and/or hip to be 16-20\% in apparently healthy women age 50 years and older (Murrillo-Uribe et al., 1999). In Mexico City, where mean age of hysterectomy was 41 years, measurements of bone mineral density at the femur and lumbar spine were positively associated with age at menopause (age at menopause included menopause by hysterectomy) (Parra-Cabrera et al., 1996).

Early age at menopause, including menopause by oophorectomy, is associated with an increased risk of osteoporotic fractures (Epstein and Goodman, 1999; Vega et al., 1994). Therefore, the study of language preference and other risk factors potentially associated with risk of hysterectomy for MexicanAmerican women living in the U.S. Southwest from 1982-1984 has current clinical significance. In contrast to most studies that examine barriers to health care services among Spanish-speaking Mexican-Americans, this study also raises the question of whether or not these English-speaking Mexican-American women were medically over-served.

\section{SUBJECTS AND METHODS}

The HHANES, 1982-1984, utilized a multistage stratified cluster survey design to sample Mexican-Americans living in the U.S. 
Southwest, Cuban Americans in Dade County, Florida, and Puerto Rican residents of the New York City area (Delgado et al., 1990). The HHANES questionnaire was administered by interviewers who were bilingual (Stroup-Benham and Trevino, 1991) and largely bicultural (Delgado et al., 1990). Within the Mexican-American population, $62 \%$ of the interviews were conducted in English, 38\% were conducted in Spanish (USDHHS, 1992). We focus on adult women who were in the Mexican-American portion of the survey and identified themselves as "Hispanic," had come to an examination center, and were age 20-74 at the time of interview. There were 1,868 women who met these criteria in the Adult Examination File, with a mean age of 38.03.

The HHANES sample design for the Mexican-American subgroup included 193 primary sampling units (PSU) which were identified and stratified to group similar counties. One PSU was selected from each stratum, then segments and finally households were selected from each PSU (Delgado et al., 1990). For the results presented here Stata software (StataCorp, 2001, Release 7.0., College Station, TX) were used, specifically the "survey" routines for means, tabulations, and logit regression, which can account for the complex survey design of the HHANES, including primary sampling unit, strata, and exam final sample weight variables included in the HHANES data (Delgado et al., 1990; Korn and Graubard, 1995; StataCorp, 2001). The women identified above (Hispanic, Mexican-American women over 19 and less than 75 years of age) were treated as a subpopulation in estimation routines rather than as a selection of cases to preserve representative weighting and ensure the proper estimation of parameters and standard errors. Results are generalizable only to the Hispanic population of the US Southwest (Delgado et al., 1990).

HHANES assessed history of hysterectomy by first asking "Have your periods stopped entirely-not counting during pregnancy?" and then "Have you had a hysterectomy?". According to the Codebook notes (USDHHS, 1992), pregnancy or lactation were not acceptable reasons for a yes response to the first question. Only women who answered yes to "Have your periods stopped entirely?" were asked about hysterectomies. Fourteen percent of the subpopulation of Mexican-American Hispanic women age $20-74$, and $55 \%$ of postmenopausal women in this group had undergone a hysterectomy. Women who responded that they had experienced hysterectomy were asked "How old were you when you had your (hysterectomy/uterus removed)?". The average age at hysterectomy among the subpopulation was 39.3. Women were also asked, "Have you ever had one or both of your ovaries removed?" and "Were both ovaries removed or only one?". Although this study is primarily concerned with determining risk factors for hysterectomy, the hormonal consequences of oophorectomy are of primary consideration when anticipating health outcomes such as osteoporosis. However, the proportion of women who did not know whether their ovaries had been removed (nearly 5\% overall), and variation in this proportion by other characteristics of interest (e.g., language), means that oophorectomy as a measure of hormonal status must be used with caution.

Independent variables of interest to us also included language preference, reproductive history, level of education, poverty status, generation of immigration, marital status, and insurance coverage. Table 1 presents the percentage distributions across these characteristics. The continuous variables of parity and education, as well as the poverty index values, were divided into substantive categories for use in the logistic regression analyses.

To identify language usage preference, we used the HHANES question "What language do you prefer?". This variable was coded in the HHANES into five categories intended to reflect the degree of Spanish language orientation: Spanish only; Mostly Spanish, Some English; Spanish and English about equally; Mostly English, Some Spanish; and English only. (This language preference variable is used here, rather than the question which simply asked which language was used most often and reported in Leidy [1998] because it implies a broader conceptualization and it has fewer missing responses. Language use was examined here only to verify the earlier results.)

Two questions from the HHANES were used to assess reproductive history: "Have you ever been pregnant?" (emphasis in the original) and "How many times have you been pregnant? Be sure to count all your pregnancies whether they ended in miscarriage, stillbirth, abortion, or live 
TABLE 1. Characteristic distributions: U.S. Mexican-American Hispanic women age 20-74, HHANES 1982-1984

\begin{tabular}{lc}
\hline & \\
& Percentage distribution* \\
\hline Language preferred & \\
Spanish only & 22.7 \\
Mostly Spanish, some English & 16.8 \\
Spanish and English about equally & 38.8 \\
Mostly English, some Spanish & 15.1 \\
English only & 7.5 \\
Reproductive History & \\
Ever pregnant & 10.8 \\
One pregnancy & 11.2 \\
Two pregnancies & 18.0 \\
Three pregnancies & 17.3 \\
More than three pregnancies & 42.6 \\
Married & 67.2 \\
Prior tubal ligation & 16.2 \\
Completed years of education & \\
Less than 6 & 22.1 \\
Zero & 5.0 \\
At least 1 but less than 6 & 17.1 \\
6 or more & 78.3 \\
At least 6 but less than 12 & 39.0 \\
12 years & 24.3 \\
13 or more & 14.7 \\
Poverty & \\
Extremely poor (<50\% of threshold) & 8.8 \\
Poor (50\%-100\% of threshold) & 23.6 \\
Precarious poverty ( $>100 \%$ and $<150 \%$ of threshold) & 19.1 \\
Not poor (150\% of threshold and above) & 48.8 \\
Generation & \\
First generation in United States & 35.3 \\
Second generation in United States & 24.2 \\
Third or more generation in United States & 39.6 \\
Medical insurance at time of interview & 55.0 \\
Enrolled in Medicaid within 12 months prior to interview & 7.9 \\
\hline
\end{tabular}

*Distributions were calculated using survey routines in Stata, which account for strata, primary sampling unit, and sample weights.

birth." Only women who had ever been pregnant were asked how many times they had been pregnant. If women were not asked how many times they had been pregnant, we considered them to have had zero pregnancies in our analyses. In keeping with earlier studies, we entered prior pregnancy as a dichotomy to compare no prior pregnancy with any number of prior pregnancies. We also examined the effect of number of pregnancies. Prior tubal ligation and whether a woman was currently married at the time of the survey were considered to be additional reproductive influences.

To assess general socioeconomic status, we used questions regarding years of education and years of education completed and a poverty index. The mean number of years of education that women in the subpopulation had completed was 8.86 . This variable was examined in our analyses as a series of categories indicating women who had not completed even 1 year of schooling (5\%), those who had completed up to 5 years (17\%), those with at least 6 years of completed schooling but who had not completed 12 years $(39 \%)$, those who had finished 12 years $(24 \%)$, and those with 13 years or more of completed education (15\%). Poverty status was drawn from the HHANES poverty index, which is family income divided by the poverty threshold (adjusted for number of family members, adult/child ratio, etc.). A value of 1 indicates that the family is at the poverty threshold. The mean poverty index estimated for the subpopulation is 1.83 , or over one-and three-quarters the poverty threshold. We divided this continuous variable into four categories to examine the effects of differing depths of poverty: extrem- 
ely poor (poverty index of less than 0.5 , or less than half of the threshold); poor (incomes resulting in a poverty index above that of the extremely poor, but not greater than the poverty threshold); precarious poverty (over the threshold, but less than $150 \%$ of that value), and not poor (at least one and one-half times the poverty level).

Generational length of time in the U.S. was used in our analyses to examine possible effects from acculturation, and to control for this as an explanation for the language preference finding. This variable was coded by HHANES as first, second, and third or higher generation in the U.S. Over onethird of the subpopulation were first-generation residents (that is, they were born in Mexico), while for nearly $40 \%$ of the subpopulation both parents had been born in the U.S. (third or more generation). (HHANES also measured acculturation with an eightvariable scale validated with a Mexican-origin population. The scale assessed language ability, country of origin of sample persons and their parents, and generation. However, as discussed below in the context of the multivariate regressions, language was the component of this measure that appears to have explanatory power and the acculturation scale was not used.)

The final set of variables we used were intended to assess whether access to health insurance in this subpopulation was a risk factor for hysterectomy. We included two questions from the survey to address this. HHANES participants were asked if they had any insurance and if they were or had been receiving Medicaid benefits within the 12 months prior to being interviewed. While over $50 \%$ of the subpopulation had insurance at the time of the interview, and only $8 \%$ had been receiving Medicaid within the prior 12 months, it is not known what coverage a woman may have had at the time of her hysterectomy. These variables may be more indicative of diffuse economic status than of actual insurance status.

We examined the effects of the above variables on the risk of hysterectomy using logistic regression models corrected for complex survey sampling design. Our core hypotheses were that age, parity, language preference, education level, and socioeconomic status (poverty index) would affect risk of hysterectomy. Additional models were created by adding other measures of acculturation (generation of immigration), reproductive influence (marital status and prior tubal ligation), and access to insurance to assess the consequences of controlling for these effects on the core model. Linear contrast tests between categories in the language, parity, education, and poverty variables were used to determine where differences in the effect on hysterectomy between categories were not significant, allowing categories to be further collapsed without loss of explanatory power. The resulting dichotomies are presented in the analyses that follow. Outliers were examined using the HosmerLemeshow and Pregibon influence statistics. To test for multicollinearity, simple correlations and the matrix of correlation coefficients were examined. Results presented are not dependent on outliers or collinearity.

\section{RESULTS}

Subsequent to the appropriate use of sample weights, the percentages of postmenopausal Mexican-American women who reported a history of hysterectomy in relation to language use were as follows: of those who spoke Spanish most often, 36.7\% reported having had hysterectomies; of those who spoke both languages most often, $61.8 \%$ reported hysterectomies; and of those who spoke English most often, $72.8 \%$ reported hysterectomies $(P<0.01)$. These findings for language use are similar to the unweighted results reported by Leidy (1998).

Returning to the broader category of language preference, among those MexicanAmerican women who underwent a hysterectomy, $33.4 \%$ of those who preferred to use only Spanish reported the removal of one or both ovaries compared to $44.1 \%$ of those who expressed any preference for English, continuing the trend of more aggressive care for English speakers. In addition, $10 \%$ of those preferring Spanish did not know whether or not their ovaries had been removed, perhaps reflecting communication difficulties at the time of hysterectomy among these women. Among those who reported having had ovaries removed, language had no bearing on whether one or both ovaries were removed. In both language groups, $60 \%$ had both ovaries removed.

Table 2 summarizes the findings of the base and subsequent models used to examine the effects of the multiple variables on the risk of hysterectomy. The base model is significant $(\mathrm{F}=113.64, P=0.0002)$. Overall 
TABLE 2. Odds ratios of risk factors for hysterectomy in U.S. Mexican-American Hispanic women age 20-74, HHANES 1982-1984

\begin{tabular}{|c|c|c|c|c|}
\hline \multirow[b]{2}{*}{ Model effects ${ }^{a}$} & \multicolumn{4}{|c|}{ Models } \\
\hline & $\begin{array}{l}\text { Base } \\
\text { model }\end{array}$ & $\begin{array}{c}\text { Other } \\
\text { acculturation }\end{array}$ & $\begin{array}{l}\text { Other } \\
\text { reproduction } \\
\text { influences }\end{array}$ & $\begin{array}{l}\text { Access } \\
\text { to insurance }\end{array}$ \\
\hline Age in 5-year increments & $\begin{array}{l}1.562^{* * * *} \\
(0.026)\end{array}$ & $\begin{array}{l}1.560 * * * \\
(0.028)\end{array}$ & $\begin{array}{l}1.561^{* * *} \\
(0.031)\end{array}$ & $\begin{array}{l}1.570 * * * \\
(0.031)\end{array}$ \\
\hline Language preference & & & & \\
\hline Any preference for English (Spanish only) & $\begin{array}{l}2.050^{* * * *} \\
(0.309)\end{array}$ & $\begin{array}{l}1.768^{* *} \\
(0.293)\end{array}$ & $\begin{array}{l}2.060^{* * *} \\
(0.364)\end{array}$ & $\begin{array}{l}2.019 * * * \\
(0.305)\end{array}$ \\
\hline $\begin{array}{l}\text { Parity } \\
\text { Ever pregnant (never pregnant) }\end{array}$ & $\begin{array}{l}3.972^{* *} \\
(1.737)\end{array}$ & $\begin{array}{l}4.078^{* *} \\
(1.857)\end{array}$ & $\begin{array}{l}4.286^{* * *} \\
(1.642)\end{array}$ & $\begin{array}{l}3.969^{* *} \\
(1.683)\end{array}$ \\
\hline $\begin{array}{l}\text { Completed years of education } \\
\text { Six or more (less than six) }\end{array}$ & $\begin{array}{l}1.622^{* *} \\
(0.317)\end{array}$ & $\begin{array}{l}1.595^{* *} \\
(0.296)\end{array}$ & $\begin{array}{l}1.701^{* *} \\
(0.340)\end{array}$ & $\begin{array}{l}1.604^{* *} \\
(0.303)\end{array}$ \\
\hline $\begin{array}{l}\text { Poverty } \\
\text { Precarious poverty and below } \\
\text { ( } 150 \% \text { of poverty threshold and above) }\end{array}$ & $\begin{array}{l}0.671^{* * * *} \\
(0.073)\end{array}$ & $\begin{array}{c}0.673^{* * * *} \\
(0.073)\end{array}$ & $\begin{array}{l}0.654^{* * *} \\
(0.069)\end{array}$ & $\begin{array}{l}0.707^{*} \\
(0.115)\end{array}$ \\
\hline $\begin{array}{l}\text { Generation } \\
\text { Second generation in United States } \\
\text { Third or higher generation (First generation) }\end{array}$ & & $\begin{array}{l}1.327 \\
(0.415) \\
1.414 \\
(0.315)\end{array}$ & & \\
\hline $\begin{array}{l}\text { Married (unmarried) } \\
\text { Prior tubal ligation (no tubal ligation) }\end{array}$ & & & $\begin{array}{c}1.018 \\
(0.207) \\
0.867 \\
(0.203)\end{array}$ & \\
\hline $\begin{array}{l}\text { Insurance (no insurance) } \\
\text { Medicaid (not enrolled) }\end{array}$ & & & & $\begin{array}{l}1.025 \\
(0.275) \\
0.555 \\
(0.182)\end{array}$ \\
\hline Model significance & 0.0002 & 0.0237 & 0.0051 & 0.0189 \\
\hline
\end{tabular}

${ }^{a}$ Logistic regression models corrected for complex survey sampling design are presented. All main effects hypotheses are included in the models. The excluded categories for each dummy variable coding set are indicated in parentheses after the last category labeled. Standard errors are included in parentheses below each coefficient.

***Significant at $P<0.01$; **Significant at $P<0.05$; *Significant at $P<0.10$.

predictive success of the base model is high, with $75 \%$ of cases correctly predicted (at a cutoff point of 0.17 ). Both sensitivity, the correct prediction of hysterectomies, and specificity, the correct prediction of nonhysterectomies, are $75 \%$ at this cutoff, considerably better than random chance.

The largest effect in the base model of hysterectomy risk is prior pregnancy, with women who had previously been pregnant almost four times as likely (odds ratio 3.972 ) to have had a hysterectomy as women who had never been pregnant, even when other variables, including age, are taken into account. Women who expressed any degree of preference for English usage over Spanish were more than twice as likely (odds ratio 2.050) to have had a hysterectomy than those who preferred to use only Spanish (the excluded category). That is, women who had the strongest orientation to the Spanish language were much less likely to have had this surgery. Age also increased the risk of hysterectomy, by over one and one-half for each additional 5 years of age (odds ratio 1.562). A woman of 40 would be over six times as likely as a woman of 20 to have had a hysterectomy $\left[\exp \left(\ln (1.562)^{*} 4\right)=6.248\right]$. The linear odds ratio across age on the logit of hysterectomy does capture a nonlinear or logistic change in the probability of a hysterectomy with increasing age. However, nonlinear relationships between age and the risk of hysterectomy were explored and age performs better than either the log of age or polynomial transformations. There appears to be only a small logarithmic decline with age controlling for other variables, and this effect is neither substantial nor improves model fit. 
Higher levels of education and economic status increased the risk of hysterectomy. Women who had completed 6 or more years of education were $60 \%$ more likely to have undergone hysterectomy than were women with less schooling (odds ratio 1.622). Poverty also significantly affected the risk of hysterectomy, with poorer women only $70 \%$ as likely to have had a hysterectomy as women who were economically more advantaged (odds ratio 0.671). Put another way, women who were not poor were one and one-half times more likely to have undergone hysterectomy than were their poorer counterparts.

In the second model in Table 2 , with controls for additional acculturation measures, the risk of hysterectomy did not vary by generation. The strength of the effect of language diminished only slightly, indicating its effect to be robust and largely independent of generation. Language is not simply a proxy for degree of acculturation. Language preference and generation are both included in the HHANES acculturation score. The acculturation score, when entered into the model instead of language and generation, has a significant effect but considerably less than language alone. Since generation has no independent effect, language appears to be the aspect of the acculturation score responsible for its effect and effects of language appear to be attenuated when confounded with generation in the acculturation score.

As can be seen from the third model in Table 2 , influences related to reproduction, (i.e., marriage and prior tubal ligation) were not significant and did not substantially alter the effects of the base model. Access to health insurance was the final addition, shown in the fourth model. Neither insurance coverage nor Medicaid enrollment were significant and neither had a substantial effect on the effects estimated in the base model.

\section{DISCUSSION}

Women in this subpopulation who had previously been pregnant were almost four times as likely (odds ratio 3.972) to have had a hysterectomy as women who had never been pregnant. This is the opposite of results reported by Meilahn et al. (1989), who found, in a random sample of women drivers in Pittsburgh, that black women who had any children were at a significantly lower risk for hysterectomy. In the HHANES sample, having had one or two prior pregnancies raised the risk of hysterectomy, but the risk did not differ significantly from no prior pregnancy. The risk of hysterectomy did increase significantly for women reporting three or four and more pregnancies. The effect of three or more prior pregnancies is to significantly increase the risk of hysterectomy over zero through two pregnancies by 2.772 times $(P=0.002)$. Other effects in the base model (e.g., language) are not substantially affected by number of prior pregnancies.

Contrary to the findings of Kjerulff et al. (1993b), Leidy (1999), and Meilahan et al. (1989), education increased the risk of hysterectomy. One difference between our results and those of earlier studies is the overall low levels of education reported by women in the HHANES sample. For example, the effect of education on hysterectomy rates in upstate New York was most obvious between women who had stopped at a college education and those who had gone on to graduate school (Leidy, 1999). In our analyses, those who had finished 6 years of school were over one and one-half times more likely (odds ratio 1.622) to have had a hysterectomy than were those women who had fewer completed years of education. To compare our results with taxonomies used by other researchers, we explored possible effects of education using more categories with fewer years of schooling in each category. The direction of effects is consistent with those estimated in the models in Table 2.

The most interesting results of this study concern the effect of language on risk of hysterectomy. It should be noted that language preference is at time of interview, not time of hysterectomy, hence we are assuming a certain degree of stability in language preference in this cohort. However, the association between language preference and hysterectomy is not a spurious effect of age or due to any change that might have occurred in language preference since hysterectomy. For either to be true, both the relationship between age and language and that between language and hysterectomy would need to have the same direction of influence. Not surprisingly, age is negatively related to English preference in the HHANES data (which is a cross-sectional sample and not a cohort study), while age is positively related to hysterectomy. These findings rule out the 
possibility that age differences are a determinant of the positive relationship reported. Age differences at the time of survey would, in fact, be likely to bias findings toward a negative relationship between English preference and hysterectomy.

Our finding that women who preferred to use English were twice as likely to report having had a hysterectomy raises questions about risk of osteoporosis as well as degree of health care utilization. An elevated risk of surgical menopause experienced 20 years before present could signal a risk factor for osteoporosis in older women now, particularly if the hysterectomies were accompanied by oophorectomies. These results suggest that practitioners should consider past and present use of English as a potential risk factor for osteoporotic fractures among older Mexican-American women.

With regard to health care utilization, our findings support Solis et al.'s (1990) assessment of the HHANES data. They concluded that language predicted the use of preventive health services (which included Pap smears and breast exams) and suggested that, "the effect of language on screening practices should not be interpreted as a cultural factor, but as an access factor, i.e., use of English favors access to services" (Solis et al., 1990:11). Access factors, such as socioeconomic differences and differences in health insurance coverage, may explain discrepancies in rates of hysterectomy between Mexican-American and Puerto Rican or Cuban-American groups (Chelimsky, 1992; Estrada et al., 1990; Mays et al., 2000; Solis et al., 1990; Torre et al., 1996; Trevino et al., 1991). However, to date, not enough attention has been paid to the possibility that language differences may affect the prevalence of hysterectomy within ethnic groups.

Studies such as this are useful as a reminder that each cohort of women is characterized by a cluster of historical characteristics and health-related behaviors. For example, the Mexican-American women surveyed in 1982-1984 would have been more likely to have had a hysterectomy in the 1970 s, when oophorectomies were more likely to have been performed (Garcia and Cutler, 1984) and when hysterectomies were still being done as a means of elective sterilization (Hibberd, 1972), particularly in traditional, Catholic communities (Morgan, 1982). In this older Mexican-American cohort it would have been the cultural norm for husbands to desire large families and disapprove of any type of birth control (Browner, 2000; Clark, 1970). This latter point may help to explain how hysterectomy rates for postmenopausal Mexican-American women could be as high as 62-73\% among those who spoke English most often. This cohort of women may have been motivated to seek a hysterectomy as a means of sterilization, and would have been better able to communicate with English-speaking physicians. In other words, it is not surprising that having had three or more prior pregnancies (compared to two or fewer pregnancies) and an ability to communicate in English increased the risk of hysterectomy in this particular cohort. We hypothesize that language use or preference had a direct effect in helping women gain access to medical care and facilitating effective communication with their physicians. In other words, language use or preference is not simply a proxy for social or economic circumstances.

Our next step is to undertake the qualitative work needed to better understand the relationship between language preference, use and facility, and the risk of hysterectomy. One hypothesis to be tested is whether language has become a less important risk factor for hysterectomy among women currently age 35-50 years. If, more than 20 years ago, women were using hysterectomies as a means of birth control, then increased access to other options (e.g., tubal ligations) may decrease the effect of language on risk of hysterectomy. A second topic for investigation is to directly test past and present language preference and current risk of osteoporotic fractures.

In conclusion, after controlling for factors other researchers have found to affect hysterectomy rates, we found that language preference still has a strong relationship to a woman's risk of hysterectomy for the Mexican-American women surveyed by HHANES, 1982-1984. Language use may be related to characteristics of the women, or to characteristics of health care providers. Whether it is the case that women who prefer English have an excess of hysterectomies or that Spanish-speaking women are not obtaining the hysterectomies they need, language should not be a decisive factor in this medical decision. 


\section{ACKNOWLEDGMENTS}

We thank Doug Anderton of the Social and Demographic Research Institute (SADRI), University of Massachusetts, Amherst, for careful review of the manuscript, and Dee Weber of SADRI for help in obtaining the HHANES data and documentation. The National Center for Health Statistics was the original source of data, distributed by the Inter-University Consortium for Political and Social Research. The authors alone are responsible for analyses, interpretations, and conclusions

\section{LITERATURE CITED}

Bauer RL, Diehl AK, Barton SA, Brender J, Deyo RA. 1986. Risk of postmenopausal hip fracture in Mexican American women. Am J Public Health 76:1020-1021.

Bernstein SJ, Fiske ME, McGlynn EA, Gifford DS. 1977. Hysterectomy: a review of the literature on indications, effectiveness, and risks. Santa Monica, CA: RAND.

Bernstein SJ, McGlynn EA, Kamberg CJ, Chassin MR, Goldberg GA, Siu AL, Brook RH. 1992. Hysterectomy: a literature review and ratings of appropriateness. Santa Monica, CA: RAND.

Bickell NA, Earp JA, Garrett JM, Evans AT. 1994. Gynecologists' sex, clinical beliefs, and hysterectomy rates. Am J Public Health 84:1649-1652.

Brett KM, Marsh JV, Madans JH. 1997. Epidemiology of hysterectomy in the United States: demographic and reproductive factors in a nationally representative sample. J Womens Health 6:309-316.

Browner CH. 2000. Situating women's reproductive activities. Am Anthropol 102:773-788.

Carlisle DM, Valdez RB, Shapiro MF, Brook RH. 1995. Geographic variation in rates of selected surgical procedures within Los Angeles County. Health Serv Res 30:27-42.

Chandra A. 1998. Surgical sterilization in the United States: prevalence and characteristics, 1965-95. Vital Health Stat 23, 20:1-33.

Chelimsky E. 1992. Hispanic access to health care: significant gaps exist: statement of Eleanor Chelimsky, Assistant Comptroller General, Program Evaluation and Methodology Division, before the House Select Committee on Aging and the Congressional Hispanic Caucus. Washington, DC: United States General Accounting Office.

Clark M. 1970. Health in the Mexican American culture: a community study, 2nd ed. Berkeley: University of California Press.

Delgado JL, Johnson CL, Roy I, Trevino FM. 1990. Hispanic Health and Nutrition Survey: methodological considerations. Am J Public Health 80(Suppl):6-10.

Derose KP, Baker DW. 2000. Limited English proficiency and Latinos' use of physician services. Med Care Res Rev 57:76-91.

Elder GH. 1985. Perspective on the life course. In: Elder $\mathrm{GH}$, editor. Life course dynamics: trajectories and transitions, 1968-1980. Ithaca: Cornell University Press. p 23-49.

Epstein S, Goodman GR. 1999. Improved strategies for diagnosis and treatment of osteoporosis. Menopause $6: 242-250$.
Estrada AL, Trevino FM, Ray LA. 1990. Health care utilization barriers among Mexican Americans: evidence from HHANES 1982-84. Am J Public Health 80(Suppl):27-31.

Farquhar CM, Steiner CA. 2002. Hysterectomy rates in the United States 1990-1997. Obstet Gynecol 99: 229-234.

Garcia CR, Cutler WB. 1984. Preservation of the ovary: a reevaluation. Fertil Steril 42:510-514.

Geller SE, Burns LR, Brailer DJ. 1996. The impact of nonclinical factors on practice variations: the case of hysterectomies. Health Serv Res 30:729-750.

Goldhaber MK, Armstrong MA, Golditch IM, Sheehe PR, Petitti DB, Friedman GD. 1993. Long-term risk of hysterectomy among 80,007 sterilized and comparison women at Kaiser Permanente, 1971-1987. Am J Epidemiol 138:508-521.

Haas S, Acker D, Donahue C, Katz ME. 1993. Variation in hysterectomy rates across small geographic areas of Massachusetts. Am J Obstet Gynecol 169:150-154.

Hibberd LT. 1972. Sexual sterilization by elective hysterectomy. Am J Obstet Gynecol 112:1076-1083.

Hillis SD, Marchbanks PA, Tylor LR, Peterson HB, for The U.S. Collaborative Review of Sterilization Working Group. 1998. Higher hysterectomy risk for sterilized than nonsterilized women: findings from the U.S. Collaborative Review of Sterilization. Obstet Gynecol 91:241-246.

James GD, Broege PA, Schlussel YR. 1996. Assessing cardiovascular risk and stress-related blood pressure variability in young women employed in wage jobs. Am J Human Biol 8:743-749.

Kjerulff KH, Guzinski GM, Langenberg PW, Stolley PD, Moye NE, Kazandjian VA. 1993a. Hysterectomy and race. Obstet Gynecol 82:757-764.

Kjerulff K, Langenberg P, Guzinski G. 1993b. The socioeconomic correlates of hysterectomies in the United States. Am J Public Health 83:106-108.

Korn EL, Graubard BI. 1995. Analysis of large health surveys: accounting for the sampling design. J R Stat Soc Series A 158:263-295.

Leidy L. 1998. Menarche, menopause, and migration: implications for breast cancer research. Am J Hum Biol 10:451-457.

Leidy, LE. 1999. Effect of exclusion: rates of hysterectomy and comparisons of age at natural menopause. Am J Hum Biol 11:687-693.

Lepine LA, Hillis SD, Marchbanks PA, Koonin LM, Morrow B, Kieke BA, Wilcox LS. 1997. Hysterectomy surveillance-United States, 1980-1993. Mor Mortal Wkly Rep CDC Surveill Summ 46:1-15.

Lilli-Blanton M, Martinez RM, Taylor AK, Robinson BG. 1993. Latina and African American women: continuing disparities in health. Int $J$ Health Serv 23:555-584.

Looker AC, Johnston CC, Wahner HW, Dunn WL, Calvo MS, Harris TB, Heyse SP, Lindsay RL. 1995. Prevalence of low femoral bone density in older U.S. women from NHANES III. J Bone Miner Res 10: 796-802.

Marks NF, Shinberg DS. 1997. Socioeconomic differences in hysterectomy: the Wisconsin Longitudinal Study. Am J Public Health 87:1507-1514.

Mays VM, Cochran SD, Sullivan JG. 2000. Health care for African-American and Hispanic women: report of perceived health status, access to care, and utilization patterns. In: Hogue CJR, Hargraves MA, Collins KS, editors. Minority health in America: findings and policy implications from the Commonwealth Fund Minority Health Survey. Baltimore: Johns Hopkins University Press. p 97-123. 
Meilahn EN, Matthews KA, Egeland G, Kelsey SF. 1989. Characteristics of women with hysterectomy. Maturitas 11:319-329.

Morgan S. 1982. Coping with a hysterectomy. New York: Dial Press. p 42-61.

Mort EA, Weissman JS, Epstein AM. 1994. Physician discretion and racial variation in the use of surgical procedures. Arch Intern Med 154:761-767.

Murrillo-Uribe A, Deleze-Hinojosa M, Aguirre E, Villa A, Calva J, Cons F, Briseno A, Gonzalez G, Morales J, Pena H, Guerrero G, Orozco J, Morales G, Elizondo J. 1999. Osteoporosis en la mujer postmenopausica mexicana. Magnitud del problema. Estudio multicentrico. Ginecol Obstet Mexico 67:227-233.

NYSDH (New York State Department of Health). 1988. Hysterectomies in New York State: a statistical profile. Albany, NY: New York State Department of Health.

Parra-Cabrera S, Hernandez-Avila M, Tamayo-y-Orozco J, Lopez-Carrillo L, Meneses-Gonzalez F. 1996. Exercise and reproductive factors as predictors of bone density among osteoporotic women in Mexico City. Calcif Tissue Int 59:89-94.

Pokras R, Hufnagel VG. 1988. Hysterectomy in the United States, 1965-84. Am J Public Health 78:852-853.

Riley MW. 1982. Aging and social change. In: Riley MW, Abeles RP, Teitelbaum MS, editors. Aging from birth to death, vol. II. Sociotemporal perspectives. Boulder, CO: Westview Press. p 11-26.

Solis JM, Marks G, Garcia M, Shelton D. 1990. Acculturation, access to care, and use of preventive services by Hispanics: findings from HHANES 1982-84. Am J Public Health 80(Suppl):11-19.
Stroup-Benham CA, Trevino FM. 1991. Reproductive characteristics of Mexican-American, mainland Puerto Rican, and Cuban-American women. Data from the Hispanic Health and Nutrition Examination Survey. JAMA 265:222-226.

Taaffe DR, Villa ML, Holloway L, Marcus R. Bone mineral density in older non-Hispanic Caucasian and Mexican-American women: relationship to lean and fat mass. Ann Hum Biol 2000; 27:331-344.

Torre A de la, Friis R, Hunter HR, Garcia L. 1996. The health insurance status of US Latino women: a profile from the 1982-84 HHANES. AJPH 86:533-537.

Trevino FM, Moyer ME, Valdez RB, Stroup-Benham CA. 1991. Health insurance coverage and utilization of health services by Mexican-Americans, mainland Puerto Ricans, and Cuban-Americans. JAMA 265: 233-237.

U.S. Department of Health and Human Services, National Center for Health Statistics. 1992. Hispanic Health and Nutrition Examination Survey, 1982-1984 [Computer file]. 7th release. Washington, DC: U.S. Dept. of Health and Human Services, National Center for Health Statistics [Producer], 1992. Ann Arbor, MI: Inter-University Consortium for Political and Social Research [Distributor].

Vega EM, Egea MA, Mautalen CA. 1994. Influence of the menopausal age on the severity of osteoporosis in women with vertebral fractures. Maturitas 19: 117-124.

Woloshin S, Bickell NA, Schwartz LM, Gany F, Welch G. 1995. Language barriers in medicine in the United States. JAMA 273:724-728. 